\title{
Recurrent acute renal failure due to a rectal villous adenoma
}

\author{
Bryan Williams, Henry J. Pearson, William W. Barrie and John Walls
}

Leicester General Hospital, Leicester LE5 4PW, UK.

\begin{abstract}
Summary: A case is reported in which a rectal villous adenoma was complicated by severe fluid and electrolyte depletion producing recurrent renal failure. The pathophysiology of the depletion syndrome and its complications are discussed. Successful management by acute haemodialysis and early surgical resection of the tumour is described.
\end{abstract}

\section{Introduction}

Rectal villous adenomas represent 1 to $3 \%$ of all bowel neoplasms but it was not until 1954 that its rare association with a fluid and electrolyte depletion syndrome was recognized. Since then several reports have described a syndrome of severe dehydration, hyponatraemia, hypochloraemia, hypokalaemia and metabolic acidosis occasionally resulting in cardiovascular collapse, renal insufficiency and death. ${ }^{1}$ This clinical picture results from the chronic fluid and electrolyte depletion in the watery, mucinous rectal discharge occasionally associated with these tumours. ${ }^{2}$ To emphasize the magnitude of the metabolic disturbance that may develop and the high index of suspicion required for diagnosis, a case of recurrent acute renal failure due to a large rectal villous adenoma is reported. The pathophysiology and management of the villous adenoma depletion syndrome are discussed.

\section{Case report}

A 69 year old female was admitted as a medical emergency with a one week history of postural dizziness, vomiting and lethargy. She attributed the symptoms to a non-steroidal anti-inflammatory drug (NSAID) recently prescribed for worsening muscle cramps. For 6 months she had noted increasing thirst and polyuria, generalized myalgia and $3 \mathrm{~kg}$ weight loss. There was no other history and in particular she denied any disturbance of her bowel habit. On examination she was very ill, grossly dehydrated, acidotic and uraemic. The blood pressure was $80 / 60 \mathrm{~mm} \mathrm{Hg}$ supine with a

Correspondence: John Walls F.R.C.P.

Accepted: 8 March 1988 postural fall to $40 / 0 \mathrm{~mm} \mathrm{Hg}$. The rest of the examination was normal. Rectal examination revealed no abnormality. Urinalysis showed blood, protein, no casts and a significant growth of coliform bacilli. Immediate investigations revealed: haemoglobin $16.2 \mathrm{~g} / \mathrm{dl}$, haematocrit 0.51 , white blood cell count $23 \times 10^{9} / 1$, serum sodium $129 \mathrm{mmol} / 1$, potassium $3.0 \mathrm{mmol} / 1$, urea $86 \mathrm{mmol} / 1$, creatinine $999 \mu \mathrm{mol} / 1$, chloride $67 \mathrm{mmol} / 1$, and glucose $6.5 \mathrm{mmol} / 1$. Arterial blood gases: $\mathrm{pH} 7.12, \mathrm{PCO}_{2} 2.2 \mathrm{kPa}, \mathrm{PO}_{2} 15.2 \mathrm{kPa}$ and bicarbonate $8 \mathrm{mmol} / \mathrm{l}$. Spot urine biochemistry showed: sodium less than $10 \mathrm{mmol} / 1$, potassium $18 \mathrm{mmol} / 1$ and urea $94 \mathrm{mmol} / 1$. Despite her marked state of dehydration the urine osmolality was only $347 \mathrm{~m}$ osmol/1 (serum $326 \mathrm{~m}$ osmol/l). She was resuscitated with 6 litres of normal saline and haemodialysed once against a high potassium dialysate. The urinary tract infection was treated with ampicillin and the NSAID stopped. Her general condition improved and with rehydration she became polyuric. Five days after admission the serum urea and electrolytes were normal apart from hypokalaemia, $3.1 \mathrm{mmol} / \mathrm{l}$. Intravenous urography was normal and upper gastrointestinal endoscopy showed scattered antral erosions. The patient was discharged with a presumptive diagnosis of acute renal failure due to hypovolaemia and urinary tract infection. The hypovolaemia was attributed to NSAID-induced gastritis and vomiting.

The patient was readmitted two weeks later with a similar clinical picture. However, on this occasion rectal examination detected the presence of a soft, mobile, fleshy mass at the finger tip. The patient once again denied any disturbance of her bowel habit. Serum biochemistry showed: sodium $130 \mathrm{mmol} / 1$, potassium $3.1 \mathrm{mmol} / 1$, urea $29 \mathrm{mmol} / 1$ and creatinine $183 \mu \mathrm{mol} / \mathrm{l}$. Spot urine electrolytes

(C) The Fellowship of Postgraduate Medicine, 1988 
were similar to those of the previous admission and the urine osmolality was inappropriately low at $434 \mathrm{~m}$ osmol/1. Confronted with these findings the patient admitted to a 15 year history of watery diarrhoea which had recently become much worse. She had become accustomed to opening her bowels up to 20 times per day, but had never sought medical attention because of her fear of cancer. A 24 hour collection of her stool confirmed 3.2 litres of a watery, mucin laden discharge containing $114 \mathrm{mmol} / 1$ of sodium, potassium $37 \mathrm{mmol} / 1$ and chloride $103 \mathrm{mmol} / \mathrm{l}$. Sigmoidoscopy confirmed the presence of a large rectal villous adenoma. During preparation for surgery she required $200 \mathrm{mmol}$ of potasium replacement and 5 litres of normal saline daily to maintain euvolaemia. At operation an unusually large rectal tumour $(17 \mathrm{~cm} \times 6 \mathrm{~cm} \times 4 \mathrm{~cm})$ was encountered in the mid rectum. This was resected and the sigmoid colon anastomosed to the distal rectum. Histologically the tumour was a benign .tubulo-villous adenoma. The patient made an uneventful post-operative recovery and continued on oral potassium supplements for several weeks until her serum electrolytes and urine concentrating capacity were restored to normal.

\section{Discussion}

The depletion syndrome is a rare, life threatening complication of the rectal villous adenoma. Characteristically there is a watery, mucinous rectal discharge with bowel actions as frequent as 20 times a day, not uncommonly for up to 15 years prior to recognition of the cause. ${ }^{3}$ At the outset, the fluid and electrolyte losses are easily compensated for by increased oral intake and renal regulation. As the tumour size increases the electrolyte and fluid losses overwhelm the compensatory mechanisms and the patient seeks medical attention. Due to the vague symptomatology, the profound metabolic disturbance and the tendency of the patients to belittle their symptoms, the initial diagnosis is often inaccurate. Diagnostic inaccuracy is compounded by the fact that even experienced digital examination of the rectum will miss accessible large tumours in up to $25 \%$ of cases due to their soft, mobile, velvetlike mucin-covered surface. ${ }^{1}$

The mechanisms accounting for the fluid and electrolyte losses that occur are unclear. Liberation from the tumour by simple transudation or active secretion exceeds the reabsorptive capacity of the colon. This is accentuated by two factors: (1) the large surface area of the tumour, itself inhibiting colonic reabsorption, and (2) possible tumour production of humoral factors that modify mucosal permeability facilitating the imbalance. ${ }^{4}$ Whilst the mechanism remains unclear, its consequences are dramatic. Typical daily losses at presentation are 1.5-3.5 litres containing sodium $40-160 \mathrm{mmol} / 1$ (average $120 \mathrm{mmol} / \mathrm{l}$ ), potassium $15-105 \mathrm{mmol} / 1$ $(60 \mathrm{mmol} / \mathrm{l})$, and chloride $80-165 \mathrm{mmol} / \mathrm{l}$ (123 $\mathrm{mmol} / \mathrm{l}) .{ }^{5}$ This results in a characteristic presentation with circulatory collapse, pre-renal uraemia, hyponatraemia, hypochloraemia, metabolic acidosis and hypokalaemia. The latter is particularly severe and often underestimated due to the co-existent metabolic acidosis.

Interestingly, the rectal losses of sodium chloride are isotonic whereas the potassium losses are often 10 times greater than the serum concentration suggesting active secretion of potassium. This is crucial to the clinical syndrome as chronic hypokalaemia not only contributes to the patient's symptoms, it also inhibits the normal compensatory mechanisms of electrolyte and water conservation. A state of diabetes insipidus develops. The failure to concentrate urine is caused by more than one mechanism, an inability to generate maximal medullary tonicity, ${ }^{6}$ impaired cellular responsiveness to anti-diuretic hormone $(\mathrm{ADH})^{7}$ and possible impaired release of $\mathrm{ADH}$ from the neurose hypophysis. ${ }^{8}$ Responsiveness to ADH is restored within a few weeks of correcting hypokalaemia. However, chronic hypokalaemia can result in morphological changes, ${ }^{9}$ notably vacuolation of the proximal and distal nephron which, if unchecked, results in chronic interstitial damage. ${ }^{10}$

Pointers to the diagnosis overlooked at the first presentation were the persistent hypokalaemia, the magnitude of the fluid replacement required to maintain euvolaemia and the inappropriately low urine osmolality.

With prompt recognition of the diagnosis recourse to haemodialysis is rarely necessary because established acute tubular necrosis is a surprisingly rare complication considering the severity of the circulatory collapse that may develop and the advanced.age of the population at risk. Reversal of the biochemical decompensation is the cornerstone of succesful management and the magnitude of the fluid and electrolyte deficit cannot be over-emphasized. An accurate daily record of urinary and colonic losses is essential to ensure adequate replacement. Once resuscitated, immediate surgical resection of the tumour is the treatment of choice. 


\section{References}

1. Shrock, L.G. \& Polk, H.C. Rectal villous adenoma producing hypokalaemia. Am J Surg 1974, 40: 54.

2. Shnitka, T.K., Friedman, M.H.W., Kidd, E.G. \& Mackenzie, W.C. Villous tumours of the rectum and colon characterized by severe fluid and electrolyte loss. Surg Gynecol Obstet 1962, 112: 609.

3. Solomon, S.S., Moran, J.M. \& Nasbeth, D.C. Villous adenoma of the rectosigmoid accompanied by electrolyte depletion. JAMA 1965, 194: 117.

4. DaCruz, G.M.G., Gardener, J.D. \& Peskin, G.W. Mechanisms of diarrhoea of villous adenomas. Am J Surg 1968, 115: 203.

5. Porter, S.D. \& Liechty, R.D. Villous adenoma in 108 patients. Am J Surg 1968, 116: 13.

6. Manitius, A., Levitin, H., Beck, D. \& Epstein, F.H. The mechanism of impairment of renal concentrating ability in potassium deficiency. $J$ Clin Invest 1960, 39: 684.
7. Rutecki, G.W., Cox, J.W. \& Robertson, G.W. Urine concentrating ability and antidiuretic hormone responsiveness in the potassium depleted dog. J Clin Lab Med 1982, 100: 53.

8. Beck, N. \& Webster, S.K. Impaired urinary concentrating ability and cyclic AMP in the K-depleted rat kidney. Am J Physiol 1976, 231: 1204.

9. Relman, A.S. \& Schwartz, W.B. Nephropathy of potassium depletion; clinical and pathological entity. $N$ Engl J Med 1956, 255: 195-203.

10. Cremer, W. \& Bock, K.D. Symptoms of chronic hypokalaemic nephropathy in man. Clin Nephrol 1977, 7: 112-119. 